ORIGINAL ARTICLE

\title{
Improvements in pain outcomes in a Canadian pediatric teaching hospital following implementation of a multifaceted, knowledge translation initiative
}

\author{
Lisa M Zhu BScPhm PharmD(Cand) ${ }^{1,2}$, Jennifer Stinson RN PhD³, Lori Palozzi RN(EC) NP-Peds MScN ACNP4, \\ Kevin Weingarten MD FRCPC ${ }^{5}$, Mary-Ellen Hogan BScPhm PharmD MSc ${ }^{6}$, Silvia Duong BScPhm PharmD ${ }^{7}$, \\ Ricardo Carbajal MD PhD ${ }^{8,9}$, Fiona A Campbell BSc MD FRCA ${ }^{10}$, Anna Taddio BScPhm MSc PhD ${ }^{3,11}$
}

\begin{abstract}
LM Zhu, J Stinson, L Palozzi, et al. Improvements in pain outcomes in a Canadian pediatric teaching hospital following implementation of a multifaceted, knowledge translation initiative. Pain Res Manage 2012;17(3):173-179.
\end{abstract}

BACKGROUND: A previous audit performed at a tertiary/quaternary pediatric hospital in Toronto, Ontario, demonstrated suboptimal assessment and treatment of children's pain. Knowledge translation (KT) initiatives (education, reminders, audit and feedback) were implemented to address identified care gaps; however, the impact is unknown.

OBJECTIVES: To determine the impact of KT initiatives on pain outcomes including process outcomes (eg, pain assessment and management practices) and clinical outcomes (eg, pain prevalence and intensity); and to benchmark additional pain practices, particularly opioid administration and painful procedures.

METHODS: Medical records at The Hospital for Sick Children (Toronto, Ontario) were reviewed on a single day in September 2007. Pain assessment and management practices, and pain prevalence and intensity in the preceding $24 \mathrm{~h}$ were recorded on a standardized data collection form. Where possible, pain outcomes were compared with previous audit results. RESULTS: Records of 265 inpatients were audited. Sixty-three per cent of children underwent a documented pain assessment compared with $27 \%$ in an audit conducted previously $(\mathrm{P}<0.01)$. Eighty-three per cent of children with documented pain received at least one pain management intervention. Overall, $51 \%$ of children received pharmacological therapy, and $15 \%$ received either a psychological or physical pain-relieving intervention. Of those assessed, $44 \%$ experienced pain in the previous $24 \mathrm{~h}$ versus $66 \%$ in the previous audit $(\mathrm{P}<0.01)$. Fewer children experienced severe pain compared with the first audit $(8.7 \%$ versus $26.1 \% ; \mathrm{P}<0.01)$. One-third of children received opioids; $19 \%$ of these had no recorded pain assessment. Among 131 children who underwent a painful procedure, $21 \%$ had a concurrent pain assessment. Painful procedures were accompanied by a painrelieving intervention in $12.5 \%$ of cases.

CONCLUSIONS: Following KT initiatives, significant improvements in pain processes (pain assessment documentation and pain management interventions) and clinical outcomes (pain prevalence, pain intensity) were observed. Further improvements are recommended, specifically with respect to procedural pain practices and opioid utilization patterns.

Key Words: Knowledge translation; Pain assessment; Pain intensity; Pain management; Pain prevalence; Painful procedures

$\mathrm{P}_{\mathrm{a}}^{\mathrm{a}}$ ain control is considered to be a fundamental human right (1). In addition to the obvious humane reasons for assessing and treating pain, there is evidence that undertreatment of pain can lead to persistent pain, alterations in nociceptive processing $(2,3)$, and emotional and psychological complications (4). Well-managed pain, on the other hand, is associated with faster recoveries, fewer complications

\begin{abstract}
Les améliorations aux issues de la douleur dans un hôpital d'enseignement pédiatrique canadien après la mise en ouvre d'une initiative de transfert du savoir multidimensionnelle
\end{abstract}

\begin{abstract}
HISTORIQUE : Une vérification antérieure, exécutée dans un hôpital pédiatrique tertiaire et quaternaire de Toronto, en Ontario, a démontré une évaluation et un traitement sous-optimaux de la douleur chez les enfants. On a adopté des initiatives de transfert du savoir (TS) (information, rappels, vérifications et rétroaction) pour corriger les lacunes des soins, mais on n'en connait pas les répercussions.

OBJECTIFS : Déterminer les répercussions des initiatives de TS sur les issues de la douleur, y compris les résultats des processus (p. ex., pratiques d'évaluation et de prise en charge de la douleur) et les issues cliniques (p. ex., prévalence et intensité de la douleur) et établir les normes de référence d'autres pratiques de contrôle de la douleur, notamment l'administration d'opioïdes et les interven-
\end{abstract} tions douloureuses.

MÉTHODOLOGIE : Les chercheurs ont révisé les dossiers médicaux de The Hospital for Sick Children de Toronto, en Ontario, au cours d'une seule journée de septembre 2007. Ils ont consigné sur un formulaire de collecte de données standardisé les pratiques d'évaluation et de prise en charge de la douleur ainsi que la prévalence et l'intensité de la douleur au cours des 24 heures précédentes. Dans la mesure du possible, ils ont comparé les issues de la douleur avec les résultats des vérifications antérieures.

RÉSULTATS : Les chercheurs ont vérifié le dossier de 265 patients hospitalisés. Soixante-trois pour cent des enfants avaient subi une évaluation de la douleur étayée, par rapport à $27 \%$ lors d'une vérification antérieure $(\mathrm{P}<0,01)$. Quatrevingt-trois pour cent des enfants ayant une douleur étayée ont reçu au moins une intervention de prise en charge de la douleur. Dans l'ensemble, $51 \%$ des enfants ont reçu une pharmacothérapie et $15 \%$, une intervention de soulagement psychologique ou physique de la douleur. Parmi les personnes évaluées, 44 \% avaient souffert de douleurs au cours des 24 heures précédentes, par rapport à $66 \%$ au cours de la vérification antérieure $(\mathrm{P}<0,01)$. Moins d'enfants avaient souffert de douleur marquée que lors de la première vérification $(8,7 \%$ par rapport à $26,1 \%$; $\mathrm{P}<0,01$ ). Le tiers des enfants avaient reçu des opioïdes; $19 \%$ d'entre eux n'avaient pas d'évaluation de douleur étayée. Chez les 131 enfants qui avaient subi une intervention douloureuse, $21 \%$ ont subi une évaluation concomitante de la douleur. Dans 12,5 \% des cas, les interventions douloureuses s'accompagnaient d'une intervention de soulagement de la douleur.

CONCLUSIONS : Après les initiatives de TS, on a observé d'importantes améliorations des processus de douleur (consignation des évaluations de la douleur et interventions de prise en charge de la douleur) et des issues cliniques (prévalence et intensité de la douleur). D’autres améliorations sont recommandées, notamment à l'égard des pratiques liées à la douleur pendant les interventions et des modes d'utilisation des opioïdes.

and decreased use of health care resources $(5,6)$. Presently, there is a plethora of evidence-based pain assessment and management techniques to assist in reducing the burden of pain among hospitalized children. Despite this, several epidemiological studies have reported a high prevalence of pain (49\% to $87 \%$ ) in hospitalized children, with more than one-half suffering from poorly managed pain (7-9). As a

Toronto. ${ }^{3}$ Child Health Evalutive Sciences, The Hon

Oncology, The Hospital for Sick Children; ${ }^{6}$ Graduate Department of Pharmaceutical Sciences, Leslie Dan Faculty of Pharmacy, University of

Toronto, Toronto, Ontario; ${ }^{7}$ Department of Pharmacy and Herzl Family Medicine Centre, Jewish General Hospital, Montreal, Quebec; ${ }^{8}$ Service

des Urgences pédiatriques, Hôpital Armand Trousseau, AP-HP, Paris, France; ${ }^{9}$ INSERM, US953, UPMC Paris 06; ${ }^{10}$ Department of Anesthesia and Pain Medicine, The Hospital for Sick Children, University of Toronto; ${ }^{11}$ Clincal Social and Administrative Pharmacy, Leslie Dan Faculty of

Pharmacy, University of Toronto, Toronto, Ontario

Correspondence: Dr Anna Taddio, Leslie Dan Faculty of Pharmacy, University of Toronto, 144 College Street, Toronto, Ontario M5S $3 \mathrm{M} 2$.

Telephone 416-978-8822, fax 416-978-1833, e-mail anna.taddio@utoronto.ca 
TABLE 1

Knowledge translation (KT) initiatives at The Hospital for Sick Children (Toronto, Ontario) since 2004

\begin{tabular}{|c|c|c|c|}
\hline $\begin{array}{l}\text { KT initiative } \\
\text { and target }\end{array}$ & Objective & Example & Timeline \\
\hline \multicolumn{4}{|l|}{ Education } \\
\hline \multirow[t]{2}{*}{ Leadership } & \multirow{2}{*}{$\begin{array}{l}\text { Establish pain as an } \\
\text { organizational priority }\end{array}$} & Invited Executive to celebrate 'Global Day Against Pain in Children' (education day) & 2005 \\
\hline & & $\begin{array}{l}\text { Addition of 'compliance with the Pain Assessment Policy' as a key performance indicator } \\
\text { for all inpatient units }\end{array}$ & 2006 \\
\hline \multirow[t]{4}{*}{$\begin{array}{l}\text { Health } \\
\text { professionals }\end{array}$} & \multirow[t]{2}{*}{$\begin{array}{l}\text { Expansion of interprofessional } \\
\text { educational sessions }\end{array}$} & $\begin{array}{l}\text { Many formal and informal teaching sessions were provided including Surgical Rounds } \\
\text { (six monthly), Paediatric Teaching Program (annually) for all new residents, fellows and staff, } \\
\text { Nursing educational presentations and Inter-professional Rounds. Sessions addressed: } \\
\text { Pain Assessment (guided by the Pain Assessment Policy); and Pain Management (guided } \\
\text { by the Pain Management Clinical Practice Guideline) }\end{array}$ & 2004, ongoing \\
\hline & & Pediatric grand rounds & 2005 \\
\hline & \multirow[t]{2}{*}{$\begin{array}{l}\text { Expansion of interprofessional } \\
\text { educational materials }\end{array}$} & $\begin{array}{l}\text { Pain Assessment Policy - development and educational roll-out: key components of the policy } \\
\text { include: referring to pain assessment as the '5th vital sign'; when and how to assess pain } \\
\text { and documentation on nursing admission assessment form; and links to pdfs of the } \\
\text { evidence-based pain intensity tools recommended for use at our organization }\end{array}$ & 2004, ongoing \\
\hline & & $\begin{array}{l}\text { Pain Management Clinical Practice Guideline - development and roll-out; key components } \\
\text { of the clinical practice guideline include: developing a pain-goal collaboratively with child } \\
\text { and family; link to the Pain Assessment Policy; and guidance on the ' } 3 \text { Ps' of pain control } \\
\text { (ie, pharmacological, physical and psychological strategies) }\end{array}$ & 2004 \\
\hline $\begin{array}{l}\text { Children and } \\
\text { families }\end{array}$ & $\begin{array}{l}\text { Provide educational materials } \\
\text { for children and families }\end{array}$ & Development of Pain Resource Centre (PRC) on www.AboutKidsHealth.ca & 2004 \\
\hline \multicolumn{4}{|l|}{ Reminders } \\
\hline Nurses & $\begin{array}{l}\text { Improve pain assessment } \\
\text { documentation }\end{array}$ & $\begin{array}{l}\text { Relocated pain assessment documentation to appear more prominently on nursing flow-sheet } \\
\text { and inclusion of check boxes to select individualized pain intensity tools }\end{array}$ & 2005 \\
\hline Doctors & Improve analgesic prescribing & $\begin{array}{l}\text { Developed option for prescribing simple analgesics (eg, acetaminophen and ibuprofen) by } \\
\text { selecting a tick box, which automatically orders appropriate medication dose and schedule }\end{array}$ & 2005 \\
\hline $\begin{array}{l}\text { Health } \\
\text { professionals }\end{array}$ & Improve pain practices & $\begin{array}{l}\text { E-mail reminder from hospital executive to use Pain resources (eg, Pain Assessment Policy } \\
\text { and Pain Management Clinical Practice Guideline) }\end{array}$ & 2005 \\
\hline \multicolumn{4}{|c|}{ Audit and feedback } \\
\hline $\begin{array}{l}\text { All professional } \\
\text { groups }\end{array}$ & Improve pain practices & $\begin{array}{l}\text { Widespread dissemination of first audit results, including feedback of unit-specific results } \\
\text { to each unit }\end{array}$ & 2004 , ongoing \\
\hline
\end{tabular}

result, many national organizations and local hospitals have developed clinical practice guidelines and consensus statements endorsing routine use of evidence-based pain management strategies (10-13). In addition, pain assessment has also become a standard for accreditation of health care institutions $(14,15)$, providing further incentive to ensure appropriate practice.

The knowledge gap

In 2004, we conducted an audit of pain practices at a large tertiary/ quaternary pediatric hospital in Toronto, Ontario. This was a one-day audit of all inpatients including patients in medical, surgical and intensive care units (ICUs). A structured questionnaire was verbally administered to collect patient demographics and determine pain prevalence, pain intensity and the type of analgesics received during admission and in the previous $24 \mathrm{~h}$. Charts were reviewed to establish the frequency of documented pain assessments in the previous $24 \mathrm{~h}$ and to verify analgesic administration. This study (9) revealed suboptimal assessment and treatment of children's pain. The results of our 2004 audit highlighted gaps between pain assessment and management recommendations and routine clinical practice, and led to the development and implementation of multifaceted knowledge translation (KT) initiatives aimed at improving pain practices. The multifaceted KT interventions included the use of education, reminders, and audit and feedback (Table 1), all of which have evidence supporting their use (16).

The purpose of the present study was to evaluate the global impact of $\mathrm{KT}$ initiatives on pain outcomes, including pain processes (eg, pain assessment documentation and pain management practices, including pharmacological, physical and psychological interventions) and clinical pain outcomes (prevalence and intensity of pain), by comparing our findings with those of our previous audit; and to benchmark further pain practices, particularly with respect to procedural pain assessment and management, and opioid utilization patterns.

\section{Settings, patients and procedures}

The present cross-sectional observational study included all inpatients at The Hospital for Sick Children (Toronto, Ontario) on the selected study day. The study was approved by the hospital's Research Ethics Board. Because the study did not influence the care of patients, consent for participation was waived by the Research Ethics Board.

The study day was a randomly selected weekday in September, 2007. Hospital staff were notified of an upcoming pain audit by e-mail and posted signs in the nursing units. To avoid a change in pain practices for the day of the audit, messages had limited information regarding the purpose of the study and did not specify the exact date of the audit (instead, a range of possible dates was given).

All inpatients younger than 18 years of age whose names appeared on the 08:00 hospital census the day of the audit were included in the study. Data were collected from patient medical records and recorded on a standardized data collection form by either health care professionals and/or trainees working in the hospital. Data collectors received a copy of the protocol and data collection form before the study and participated in a $2 \mathrm{~h}$ training session on the morning of the audit. The data collectors were assigned to different units within the hospital, where they collected data for all the inpatients in those units. Study investigators participated in the data collection, and were available to answer questions and provide clarification as required. 


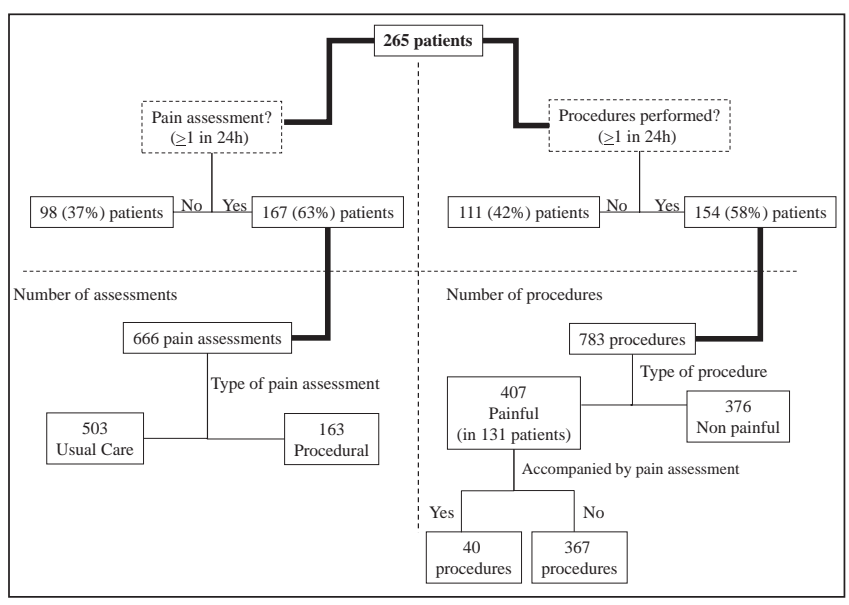

Figure 1) Diagram showing the analysis of both documented pain assessment and procedural prevalence and pain assessment including subgroup analyses for each

\section{Demographics}

Demographic variables included age, sex, type of service (eg, medical, surgical, ICU) and whether the child was intubated at the time of the audit.

\section{Pain assessment and management}

As per the previous audit (9), information was collected on the frequency of pain assessment documentation, type of pain assessment tool used, pain intensity rating and pain management interventions for the preceding $24 \mathrm{~h}$. Pain management interventions included the following: pharmacological (simple analgesics [eg, acetaminophen, nonsteroidal anti-inflammatory drugs (NSAIDs)], opioids [eg, codeine, morphine, hydromorphone and fentanyl] and adjuvant agents [eg, gabapentin, ketamine, amitriptyline and clonidine); physical (eg, heat or cold therapy); and psychological (eg, distraction) strategies. Finally, the type and number of painful procedures and procedural pain assessment and management practices were documented during the same $24 \mathrm{~h}$ period. Figure 1 illustrates the flow of data that were collected in the study.

\section{Study outcomes}

Rates of documented pain assessments were determined during usual care and at the time of procedures. Pain intensity scores obtained from individual pain tools were converted to a common four-level metric (none, mild, moderate and severe pain) to summarize results. The scores for the Verbal Descriptive Scale were converted into these four levels using the cut-off points validated by Jones et al (17) whereby no pain was converted to none; a little pain to mild; medium pain to moderate; and a lot of pain to severe. Scores on the numerical rating scale (NRS) were also converted as follows: $0=$ no pain, 1 to $3=$ mild pain, 4 to $6=$ moderate pain and $>6=$ severe pain (17). The Face, Legs, Arms, Cry and Consolability scale was converted using the same cut-off points as the NRS. For the Premature Infant Pain Profile, scores of 0 to 6 were converted to none, scores of 7 to 12 to moderate pain, and scores $>12$ to severe pain. Pain assessed without a documented tool (eg, physiological parameters) or by an unspecified tool were not included. The number of procedures, defined as any medical, nursing, surgical, diagnostic or therapeutic activity, were tabulated with a specific focus on painful procedures. Using the definition proposed by Carbajal et al (18), a procedure was considered to be painful if it invaded the child's bodily integrity, causing skin or mucosal injury by the introduction or removal of foreign material into the airway, or digestive or urinary tract. Additional procedures were considered to be painful, as designated in previous studies (eg, adhesive tape removal) (18-21). Finally, the percentage of children with documented pharmacological, physical and psychological interventions during usual care and at the time of procedures were calculated.
TABLE 2

Demographic characteristics of children included in one-day audit $(n=265)$

\begin{tabular}{lc}
\hline Characteristic & $\mathbf{n}(\%)$ \\
\hline Age, years & \\
$<1$ & $99(37.4)$ \\
$1-3$ & $33(12.5)$ \\
$4-6$ & $31(11.7)$ \\
$7-12$ & $47(17.7)$ \\
$13-18$ & $55(20.8)$ \\
Male sex & $147(55.5)$ \\
Female sex & $118(44.5)$ \\
Intubated at the time of audit & $47(17.7)$ \\
Patients per service type & \\
$\quad$ Medical unit & $121(45.7)$ \\
Surgical unit & $89(33.5)$ \\
Intensive care unit & $55(20.8)$ \\
\hline
\end{tabular}

\section{Data analysis}

Data were analyzed using Excel 2010 (Microsoft Corporation, USA). Descriptive statistics were used to summarize data, including means and SDs, medians and interquartile ranges (IQRs) for continuous data, and frequencies and percentages for categorical data. Comparisons in the median number of procedures among children under the care of different medical services (ie, medical, surgical, intensive care) were performed using the Kruskal-Wallis $\mathrm{H}$ test. Post hoc comparisons were performed using the Mann-Whitney $U$ test. $\chi^{2}$ tests were used to compare percentages between the current and previous audit (9) in pain assessment documentation, pain management, pain prevalence and pain intensity. $\mathrm{P}<0.05$ was considered to be statistically significant.

\section{Demographics}

\section{RESULTS}

A total of 265 children were included. The median age was 4.2 years (IQR 0.3 to 12.0 , mean [ \pm SD] age $6.1 \pm 6.2$ years). The proportion of children admitted to each service type is summarized in Table 2.

\section{Pain assessment}

In total, 167 (63\%) of the 265 children had at least one documented pain assessment in the previous $24 \mathrm{~h}$ (Figure 1). Thirty per cent of children had one to two assessments, $17 \%$ had three to five assessments, and $16 \%$ had six or more assessments in the previous $24 \mathrm{~h}$. There were 666 pain assessments documented for these 167 children, translating to a median of three (IQR 1 to 6) assessments per child. Children on surgical units (78\%) and ICU (78\%) were more likely to have a documented pain assessment compared with patients on medical units (46\%; $\mathrm{P}<0.01$ for both analyses).

The pain assessment tools and the ages of children in whom they were used are presented in Table 3. The NRS was the most frequently used tool to assess pain.

\section{Procedural prevalence and pain assessment}

A total of 154 (58\%) children underwent 783 procedures (Figure 1). The most commonly performed painful and nonpainful procedures are summarized in Table 4, which account for $95 \%$ of all procedures. Forty-nine per cent of children had at least one painful procedure documented (mean $3.1 \pm 3.3$ per child, median 2, range 1 to 20 , IQR 1 to 4$)$. Twenty-eight children $(21.4 \%)$ had a documented pain assessment at the time of the procedure. Overall, few painful procedures were accompanied by a documented pain assessment at the time of the procedure (Figure 1).

A greater proportion of children underwent painful procedures in the ICU (81.8\%) when compared with children in medical units $(51.2 \%)$ or surgical units $(27 \%), \mathrm{P}<0.001$ for both comparisons. Children in the ICU had an average of $4.9 \pm 4.0$ (median 4 , range 1 to 15 , IQR 2 to 7 ) 
TABLE 3

Type and frequency of pain assessment tools used to perform pain assessments in the previous $24 \mathrm{~h}$

\begin{tabular}{|c|c|c|}
\hline $\begin{array}{l}\text { Tools used in pain } \\
\text { assessments }\end{array}$ & n (\%) & $\begin{array}{l}\text { Children assessed, } \\
\text { median age (range) }\end{array}$ \\
\hline $\begin{array}{l}\text { Premature Infant Pain } \\
\text { Profile }\end{array}$ & $89(13.4)$ & $\begin{array}{c}2.6 \text { weeks } \\
\text { (2 days }-4.8 \text { months) }\end{array}$ \\
\hline $\begin{array}{l}\text { Face, Legs, Activity, Cry, } \\
\text { Consolability Scale }\end{array}$ & $238(35.7)$ & $\begin{array}{c}5.9 \text { months } \\
\text { (11 days-12.1 years) }\end{array}$ \\
\hline Numerical Rating Scale & $247(37.1)$ & $\begin{array}{c}10.1 \text { years } \\
\text { (4.9 weeks-18.4 years) }\end{array}$ \\
\hline Verbal Descriptive Scale & $16(2.4)$ & $\begin{array}{c}8.9 \text { years } \\
(4.2-14.1 \text { years })\end{array}$ \\
\hline $\begin{array}{l}\text { Physiological (ie, changes } \\
\text { in heart rate) }\end{array}$ & $39(5.9)$ & $\begin{array}{c}2.4 \text { weeks } \\
\text { (2 days }-3.7 \text { months) }\end{array}$ \\
\hline Not specified/none & $37(3.5)$ & 6.5 years ( 2 weeks-17.8 years) \\
\hline Total & $666(100)$ & \\
\hline
\end{tabular}

painful procedures per day compared with $1.7 \pm 1.2$ (median 1 , range 1 to 4 , IQR 1 to 2 ) for children in surgical units and $2.3 \pm 2.8$ (median 1.5 , range 1 to 20 , IQR 1 to 2.8 ) for children in medical units $(\mathrm{P}<0.001$ for both analyses). There was no significant difference between surgical and medical units $(\mathrm{P}=0.14)$.

Pain prevalence

Of the 167 children with at least one documented pain assessment, 66 (44\%) experienced some pain in the preceding $24 \mathrm{~h}$ (Table 5). Patients on surgical units were more likely to experience pain compared with those on medical units $(56 \%$ versus $29 \%$; $<<0.01)$. Of the 40 painful procedures accompanied by a documented pain assessment, $12(29.3 \%)$ were rated as painful.

Pain intensity

For $89 \%$ of the 167 children with at least one documented pain assessment, pain severity could be summarized using the categories of none, mild, moderate and severe (Table 5). More than two-thirds of patients experienced no pain or only mild pain in the previous $24 \mathrm{~h}$.

\section{Pain management}

Of the 265 children, 156 (58.9\%) received at least one documented pain management intervention (Table 6). Patients on surgical units $(73 \%)$ and in the ICU $(84 \%)$ were more likely to receive a painrelieving intervention compared with patients on medical units $(37 \%$; $\mathrm{P}<0.01$ for both analyses).

In the 66 children with documented pain (either mild, moderate or severe), $55(83.3 \%)$ received a pain management intervention. Fiftyfour $(81.8 \%)$ had documentation of at least one pharmacological intervention (analgesic and/or adjuvant), six (9.1\%) received a physical intervention and five (7.6\%) received a psychological intervention (Table 7).

Eighty-four (31.7\%) children received an opioid in the preceding $24 \mathrm{~h}$. Of these, 16 (19\%) had no documented pain assessment, 48 (57\%) were concomitantly receiving acetaminophen with or without an NSAID, and $10(11.9 \%)$ were receiving adjuvant therapy. Dosing frequency details were available for 74 (88\%) children, 40 (54\%) of whom received a continuous infusion.

The prevalence of opioid use according to pain intensity was as follows: $100 \%$ of the 13 children with severe pain, $64.7 \%$ of the 34 children with moderate pain and $57.9 \%$ of the 19 children with mild pain.

For the 407 painful procedures performed in 131 children, 51 (12.5\%) were accompanied by a pain management intervention at the time of the procedure. A pain management intervention was administered at sometime within the $24 \mathrm{~h}$ period for $284(69.8 \%)$ of procedures (Table 4).

Comparison with previous audit

Table 5 presents a comparison between the previous and present audit results. The frequency of pain assessment documentation was significantly higher, the prevalence of pain was significantly lower, and the proportion of children with severe pain was significantly lower in the present audit. A significantly higher proportion of patients experiencing severe pain received an opioid in the preceding $24 \mathrm{~h}$ in the present audit.

\section{TABLE 4}

Documented pain management interventions administered to recipients of procedures ( $n=783$ ), according to procedure type

\begin{tabular}{|c|c|c|c|c|c|c|}
\hline \multirow[b]{3}{*}{ Procedure type } & \multirow[b]{3}{*}{ Procedures } & \multicolumn{5}{|c|}{ Pain management intervention administered to recipients of procedure } \\
\hline & & \multicolumn{4}{|c|}{ At time of procedure } & \multirow{2}{*}{$\begin{array}{l}\text { Anytime in prev } 24 \mathrm{~h} \\
\text { Any pharmacologica }\end{array}$} \\
\hline & & Any pharmacological & Any physical & Any psychological & Any intervention & \\
\hline \multicolumn{7}{|l|}{ Painful* } \\
\hline \multicolumn{7}{|l|}{$\operatorname{Mild}^{\dagger}$} \\
\hline Nasal or tracheal aspiration & $100(12.8)$ & $1(1)$ & $0(0.0)$ & $0(0.0)$ & $1(1)$ & $67(67)$ \\
\hline Primary tube or catheter removal & $15(1.9)$ & $0(0.0)$ & $2(13.3)$ & $2(13.3)$ & $2(13.3)$ & $10(66.7)$ \\
\hline Chest physiotherapy & $11(1.4)$ & $1(9.1)$ & $0(0.0)$ & $0(0.0)$ & $1(9.1)$ & $6(54.5)$ \\
\hline Other painful procedures & $11(1.4)$ & $5(45.5)$ & $2(18.2)$ & $0(0.0)$ & $7(63.6)$ & $9(81.8)$ \\
\hline \multicolumn{7}{|l|}{ Mild to moderate $^{\dagger}$} \\
\hline Dressing change & $39(5.0)$ & $2(5.1)$ & $1(2.6)$ & $2(5.1)$ & $4(10.3)$ & $23(59.0)$ \\
\hline Tape removal and others (electrodes) & $37(4.7)$ & $3(8.1)$ & $0(0.0)$ & $0(0.0)$ & $3(8.1)$ & $22(59.5)$ \\
\hline Insertion of nasogastric tube & $18(2.3)$ & $0(0.0)$ & $2(11.1)$ & $1(5.6)$ & $2(11.1)$ & $10(55.6)$ \\
\hline \multicolumn{7}{|l|}{ Moderate to severe $^{\dagger}$} \\
\hline Heel stick & 59 (7.5) & $1(1.7)$ & $12(20.3)$ & $0(0.0)$ & $13(22.0)$ & $37(62.7)$ \\
\hline Peripheral intravenous insertion & $35(4.5)$ & $2(5.7)$ & $0(0.0)$ & $0(0.0)$ & $2(5.7)$ & $19(54.3)$ \\
\hline Venous stick for blood draw & $28(3.6)$ & $0(0.0)$ & $0(0.0)$ & $0(0.0)$ & $0(0.0)$ & $15(53.6)$ \\
\hline Insertion of PICC line & $21(2.7)$ & $6(28.6)$ & $2(9.5)$ & $0(0.0)$ & 7 (33.3) & $15(71.4)$ \\
\hline \multicolumn{7}{|l|}{ Nonpainful } \\
\hline Routine care & 321 (41.0) & $8(2.5)$ & $52(16.2)$ & $13(4.0)$ & $61(19.0)$ & $187(58.3)$ \\
\hline X-ray & $36(4.6)$ & $0(0.0)$ & 4 (11.1) & $3(8.3)$ & 4 (11.1) & $27(75.0)$ \\
\hline Ultrasound & 15 (1.9) & $1(6.7)$ & $0(0.0)$ & $3(20.0)$ & $4(26.7)$ & $12(80.0)$ \\
\hline
\end{tabular}

Data presented as $n$ (\%). *Procedures were considered painful according to the definition proposed by Carbajal et al (18); ${ }^{\dagger}$ Pain severity of different procedures was according to categorization by Stevens et al (21). Note: table does not include procedure types that accounted for less than $1 \%$ of the 783 procedures. PICC Peripherally inserted central catheter; prev Previous 
TABLE 5

Comparison of results between first and second audit

\begin{tabular}{|c|c|c|c|}
\hline & \multicolumn{2}{|c|}{ Audit year } & \multirow[b]{2}{*}{$\mathbf{P}$} \\
\hline & $\begin{array}{c}2004 \\
(n=241)\end{array}$ & $\begin{array}{c}2007 \\
(n=265)\end{array}$ & \\
\hline $\begin{array}{l}\text { Children with documented pain } \\
\text { assessment in previous } 24 \mathrm{~h}\end{array}$ & $27^{*}$ & 63 & $<0.01$ \\
\hline Children with pain in previous $24 \mathrm{~h}$ & 66 & $44^{\dagger}$ & $<0.01$ \\
\hline \multicolumn{4}{|l|}{ Pain intensity } \\
\hline None & 34.4 & $55.7^{\dagger}$ & $<0.01$ \\
\hline Mild pain & 16.2 & $12.8^{\dagger}$ & 0.52 \\
\hline Moderate pain & 23.2 & $22.8^{\dagger}$ & 0.03 \\
\hline Severe pain & 26.1 & $8.7^{\dagger}$ & $<0.01$ \\
\hline $\begin{array}{l}\text { Patients with severe pain who received an } \\
\text { opioid }\end{array}$ & 41 & 100 & $<0.01$ \\
\hline
\end{tabular}

Data presented as \% unless otherwise indicated. ${ }^{*} n=212$ children; ${ }^{+} n=149$ children whose pain severity could be summarized using the categories of none, mild, moderate and severe

\section{DISCUSSION}

While previous studies have demonstrated that various quality improvement interventions improve process outcomes (eg, pain assessment documentation, analgesic administration) (22-26), to our knowledge, the present study was the first to also show improvements in clinical outcomes (eg, pain intensity scores) for patients following implementation of multifaceted KT interventions. Our audit of pain assessment and pain management practices revealed that there were significantly higher rates of pain assessments. Pain management interventions were also more frequently administered, with the use of multimodal analgesia and continuous opioid infusions. Fewer children experienced pain, and pain intensity was significantly lower.

More specifically, we found that pain was assessed in approximately two-thirds of children. This represents a more than twofold increase since the implementation of a targeted pain KT dissemination plan across the hospital. However, only one-fifth of children had pain assessed at the time of painful procedures. One-half of the children experienced at least one painful procedure, with an average of three per child per day. Pain prevalence was lower in the present audit when compared with our initial audit, with slightly less than one-half of children with a documented assessment experiencing pain in the preceding $24 \mathrm{~h}$. In addition, significantly fewer children in the present audit experienced severe pain. More than one-half of children received a documented pain management intervention, with pharmacological interventions being the most common. All patients who experienced severe pain received an opioid, which also represents an improvement from the first audit.

Interestingly, approximately one-third of all children received an opioid in the preceding $24 \mathrm{~h}$, with morphine being the most common $(16 \%)$, followed by codeine. Surprisingly, approximately one-fifth of these patients had no documented pain assessment during this time frame. It is important that pain be reassessed soon after any pharmacological intervention to guide further interventions and ensure pain relief goals are achieved. Of the patients who received an opioid, more than one-half were given concomitant acetaminophen, with or without an NSAID, and approximately $10 \%$ were given adjuvant therapy, indicating use of multimodal analgesia practice. This is in keeping with the WHO's standard of providing multimodal analgesia and reflects an improvement over the first audit, in which analgesic interventions consisted primarily of single agents. Another positive finding is that almost one-half of opioids were administered by continuous infusion. This suggests that children in pain were being administered regularly scheduled analgesia, which is preferable to reactive, symptom-triggered administration.

The use of physical and psychological measures to reduce perception of pain and enhance comfort was highlighted in the hospital
TABLE 6

Most frequently documented pain management interventions in the preceding $24 \mathrm{~h}$

\begin{tabular}{|c|c|c|c|}
\hline Intervention & $\begin{array}{c}\text { Children } \\
\text { receiving } \\
\text { intervention, } \mathbf{n}\end{array}$ & $\begin{array}{c}\text { Children in } \\
\text { intervention } \\
\text { category, \% }\end{array}$ & $\begin{array}{l}\% \text { of all } \\
\text { children } \\
(n=265)\end{array}$ \\
\hline \multicolumn{4}{|l|}{ Pharmacological $(n=134)$} \\
\hline \multicolumn{4}{|l|}{ Opioid } \\
\hline Codeine & 23 & 17.2 & 8.7 \\
\hline Morphine & 44 & 32.8 & 16.6 \\
\hline Hydromorphone & 13 & 9.7 & 4.9 \\
\hline Fentanyl & 17 & 12.7 & 6.4 \\
\hline Epidural with opioid & 5 & 3.7 & 1.9 \\
\hline Other & 2 & 1.5 & 0.8 \\
\hline Regional anaesthetic (nerve block) & 7 & 5.2 & 2.6 \\
\hline \multicolumn{4}{|l|}{ Simple analgesics } \\
\hline Nonsteroidal anti-inflammatory & 24 & 17.9 & 9.1 \\
\hline Acetaminophen & 85 & 63.4 & 32.1 \\
\hline \multicolumn{4}{|l|}{ Adjuvant } \\
\hline Benzodiazepines & 16 & 11.9 & 6.0 \\
\hline Chloral hydrate & 6 & 4.5 & 2.3 \\
\hline Carbamazepine or phenobarbital & 6 & 4.5 & 2.3 \\
\hline Ketamine or propofol & 5 & 3.7 & 1.9 \\
\hline Gabapentin or amitriptyline & 3 & 2.2 & 1.1 \\
\hline Clonidine & 2 & 1.5 & 0.8 \\
\hline Other & 8 & 6.0 & 3.0 \\
\hline \multicolumn{4}{|l|}{ Psychological (n=16) } \\
\hline Preparation or education & 8 & 50.0 & 3.0 \\
\hline Distraction & 13 & 81.3 & 4.9 \\
\hline Relaxation & 2 & 12.5 & 0.8 \\
\hline \multicolumn{4}{|l|}{ Physical (n=32) } \\
\hline Pacifier & 8 & 25.0 & 3.0 \\
\hline Breastfeeding during procedure & 1 & 3.1 & 0.4 \\
\hline Heat or cold therapy & 9 & 28.1 & 3.4 \\
\hline Physical therapy & 1 & 3.1 & 0.4 \\
\hline Therapeutic touch & 22 & 68.8 & 8.3 \\
\hline
\end{tabular}

TABLE 7

Pain management interventions in the preceding $24 \mathrm{~h}$ in children with documented pain

\begin{tabular}{lccc}
\hline & \multicolumn{3}{c}{ Highest pain intensity during previous 24 $\mathbf{h}, \mathbf{n}(\%)$} \\
\cline { 2 - 4 } Intervention type & Mild $(\mathbf{n = 1 9 )}$ & Moderate $(\mathbf{n = 3 4 )}$ & Severe $(\mathbf{n = 1 3})$ \\
\hline Any pharmacological & $14(73.7)$ & $27(79.4)$ & $13(100.0)$ \\
Any physical & $1(5.3)$ & $2(5.9)$ & $3(23.1)$ \\
Any psychological & $1(5.3)$ & $3(8.8)$ & $1(7.7)$ \\
Any type of intervention* & $14(73.7)$ & $28(82.4)$ & $13(100.0)$ \\
\hline
\end{tabular}

*May include pharmacological, physical, psychological or a combination thereof

Pain Management Clinical Practice Guideline and staff education was provided on these strategies (Table 1). Despite this, only $15 \%$ of children were recorded as receiving a physical or psychological intervention. Previous studies have also reported that nonpharmacological pain-relieving strategies are infrequently used (27-29). Because the present study involved an audit of patient medical records, it was not possible to determine whether nonpharmacological measures were not performed, or whether they were performed but not recorded. It is, however, important to acknowledge that nurses' and other health care providers' documentation should reflect all care provided to patients.

It was disappointing that only a small proportion of children received a pain management intervention at the time of a painful procedure, despite considerable evidence of effective procedural pain management strategies $(12,13)$. It is somewhat reassuring, however, 
that more than two-thirds had received an intervention in the preceding $24 \mathrm{~h}$. Notably, procedures were considered to be painful according to the definition proposed by Carbajal et al (18), yet from the subset of painful procedures that were accompanied by a documented pain assessment, only one-third were actually rated as being painful. Given these findings, the definition of painful procedures and apparent lack of procedural assessment and analgesia administration warrants further investigation. Specifically, the added benefit of breakthrough analgesia in the presence of ongoing analgesia needs to be documented.

Despite the improvements in pain processes and patient outcomes, there remains room for improvement. One-third of children had no documented pain assessment and pain assessments were infrequently documented during painful procedures. One-fifth of children who were given opioids did not have documentation of pain assessment. Few patients had either physical or psychological interventions documented.

Our findings have informed the development and implementation of additional KT initiatives (eg, revised and expanded educational sessions and materials). Development of an online interprofessional pain curriculum and a five-week interprofessional pain clinical placement education program for health care trainees is also underway. Numerous reminders of pain resources at the hospital exist (posters and e-mails), and the results of this audit are being disseminated as a further 'audit and feedback' intervention. In addition, audits are being planned for the future.

\section{Study limitations}

Interpretation of these results should acknowledge several limitations. First, data were collected by a retrospective review of patient medical records, and documentation may have been incomplete and/or variable. Together, these factors limit our ability to extrapolate the results to actual practices. Nurses and other health care providers may be performing unrecorded pain assessments and providing undocumented pain-relieving (physical or psychological) interventions. Second, some children were excluded from the analysis of pain prevalence and pain intensity because pain was assessed using inappropriate or less reliable methods such as physiological parameters; however, this only represents a small percentage $(<10 \%)$ of all assessments. Overall, the data suggest that the majority of pain assessments were performed using an appropriate tool. In addition, caution should be taken when interpreting comparisons between the present and previous audits because there were some methodological differences. In the previous audit (9), children and/or caregivers were asked during an interview to recall pain in the previous $24 \mathrm{~h}$, whereas in the present audit, this was determined from documented pain scores in the medical chart. It is reassuring to note that other studies have shown strong associations between recall and actual average pain ratings for the same time frame (30); thus, this was considered to be an appropriate comparison. When interpreting the relative effectiveness of the $\mathrm{KT}$ initiatives, it is important to note that the impact of audit and feedback is likely to be greater when baseline adherence to recommended practice is low and when feedback is delivered more intensively (31). The nonexperimental nature of the study prevents us from concluding that the changes were definitely caused by our KT interventions rather than other factors such as changes due to time. However, we believe it is very unlikely that the observed improvements could have been achieved without our KT interventions. Finally, it is not possible to evaluate the impact of the individual components of the multifaceted KT intervention on the pain outcomes. The combined strategies likely contributed to the overall positive impact.

\section{CONCLUSIONS}

After implementation of a multifaceted KT intervention, we observed improvements in both process and clinical outcomes including significantly higher rates of documented pain assessment and pain management interventions, and significantly lower pain prevalence, with fewer children experiencing severe pain. Although these results are encouraging, there remains room for improvement. This information has been used to revise existing KT initiatives and develop new ones to support the adoption of best practices, and future audits are planned to assess their effectiveness.

ACKNOWLEDGEMENTS: The following individuals helped with aspects of data acquisition, data entry, data analysis and/or manuscript review: Carmen Lin, Heather Harris, Kathryn Walker, Maria Rugg, Jennifer Tyrrell, Patricia Cimerman, Ali Jamal, Suganthan Thivakaran, Jane Wang, Charmy Vyas, Charles Zhu and Judith Versloot.

\section{REFERENCES}

1. Brennan F, Carr DB, Cousin M. Pain management: A fundemental human right. Pain Med 2007;105:205-21.

2. Grunau RE, Holsti L, Peters JWB. Long-term consequences of pain in human neonates. Semin Fetal Neonatal Med 2006;11:268-75.

3. Hermann C, Hohmeister J, Demirakca S, Zohsel K, Flor H. Long-term alteration of pain severity in school-aged children with early pain experiences. Pain 2006;125:278-85.

4. Schechter NL, Alen DA, Hanson K. Status of pediatric pain control: A comparison of hospital analgesic usage in children and adults. Pediatrics 1986;77:11-15.

5. Liu S, Carpenter RL, Neal JM. Epidural anesthesia and analgesia. Their role in postoperative outcome. Anesthesiology 1995;82:1474-506.

6. Wasylak TJ, English MJM, Jeans M-E. Reduction of postoperative morbidity following patientcontrolled morphine. Can J Anaesth 1990;37:726-31.

7. Johnston CC, Abbott FV, Gray-Donald K, Jeans ME. Survey of pain in hospitalized patients aged 4-14 years. Clin J Pain 1992;8:154-63.

8. Cummings EA, Reid GJ, Finley A, McGrath PJ, Ritchie JA. Prevalence and source of pain in pediatric inpatients. Pain 1996;68:25-31.

9. Taylor EM, Boyer K, Campbell FA. Pain in hospitalized children: A prospective cross-sectional survey of pain prevalence, intensity, assessment and management in a Canadian pediatric teaching hospital. Pain Res Manag 2008;13:25-32.

10. American Academy of Pediatrics and American Pain Society. The assessment and management of acute pain in infants, children and adolescents. Pediatrics 2001;108:793-7.

11. American Academy of Pediatrics and Canadian Paediatric Society. Prevention and management of pain in the neonate: An update. Pediatrics 2006;118:2231-41.

12. Paediatrics \& Child Health Division, The Royal Australasian College of Physicians. Management of procedure-related pain in children and adolescents. J Paediatr Child Health 2006;42:S1-S29.

13. Lago P, Garetti E, Merazzi D, et al. Guidelines for procedural pain in the newborn. Acta Paediatrica 2009;98:932-9.

14. Phillips DM. JCAHO pain management standards are unveiled. Joint Commission on Accreditation of Healthcare Organizations. JAMA 2000;284:428-9.

15. Canadian Council on Health Services Accreditation. <http://www.accreditation.ca> (Accessed May 18, 2011).

16. Grimshaw JM, Shirran L, Thomas R, et al. Changing provider behaviour: An overview of systematic reviews of interventions. Med Care 2001;39(Supp2):II-2-II-45.

17. Jones KR, Vojir CP, Hutt E, Fink R. Determining mild, moderate, and severe pain equivalency across pain-intensity tools in nursing home residents. J Rehabil Res Dev 2007;44:305-14.

18. Carbajal R, Rousset A, Danan C, et al. Epidemiology and treatment of painful procedures in neonates in intensive care units. JAMA 2008;300:60-70.

19. Porter FL, Wolf CM, Gold J, et al. Pain and pain management in newborn infants: A survey of physicians and nurses. Pediatrics 1997;100:626-32.

20. Porter FL, Wolf CM, Miller JP. Procedural pain in newborn infants: The influence of intensity and development. Pediatrics 1999;104:e13. 
21. Stevens BJ, Abbott LK, Yamada J, et al. Epidemiology and management of painful procedures in children in Canadian hospitals. CMAJ 2011;183:E403-E410.

22. Treadwell MJ, Franck LS, Vichinsky E. Using quality improvement strategies to enhance pediatric pain assessment. Int J Qual Health Care 2002;14:39-47.

23. Jordan-Marsh M, Hubbard J, Watson R, Deon Hall R, Miller P, Mohan $\mathrm{O}$. The social ecology of changing pain management: Do I have to cry? J Pediatr Nurs 2004;19:193-203.

24. Simons J, MacDonald LM. Changing practice: Implementing validated paediatric pain assessment tools. J Child Health Care 2006;10:160-76.

25. Ellis JA, McCleary L, Blouin R, et al. Implementing best practice pain management in a pediatric hospital. J Spec Pediatr Nurs 2007;12:264-77.

26. Megens JH, van der Werff DB, Knape JT. Quality improvement: Implementation of a pain management policy in a university pediatric hospital. Paediatr Anaesth 2008;18:620-7.
27. Polkki T, Pietila AM, Vehvilamen-Julkunen K. Hospitalized children's descriptions of their experiences with postsurgical pain relieving methods. Int J Nurs Stud 2003;40:33-44.

28. Jacob E, Puntillo KA. A survey of nursing practice in the assessment and management of pain in children, Pediatr Nurs 1999;25:278-86.

29. Twycross A. Children's nurses' post-operative pain management practices: An observational study. Int J Nurs Stud 2007;44:869-81.

30. Jensen MP, Mardekian J, Lakshminarayana M, Boye ME. Validity of 24-h recall ratings of pain severity: Biasing effects of "peak" and "end" pain. Pain 2008;137:422-7.

31. Jamtvedt G, Young JM, Kristoffersen DT, O'Brien MA, Oxman AD. Audit and feedback: Effects on professional practice and health care outcomes. Cochrane Database Syst Rev 2006;(2):CD000259. DOI: $10.1002 / 14651858 . C D 000259 . p u b 2$ 


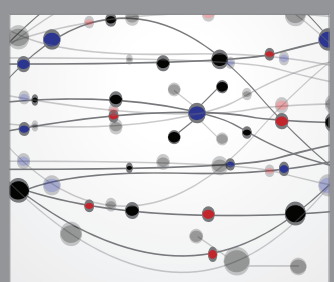

The Scientific World Journal
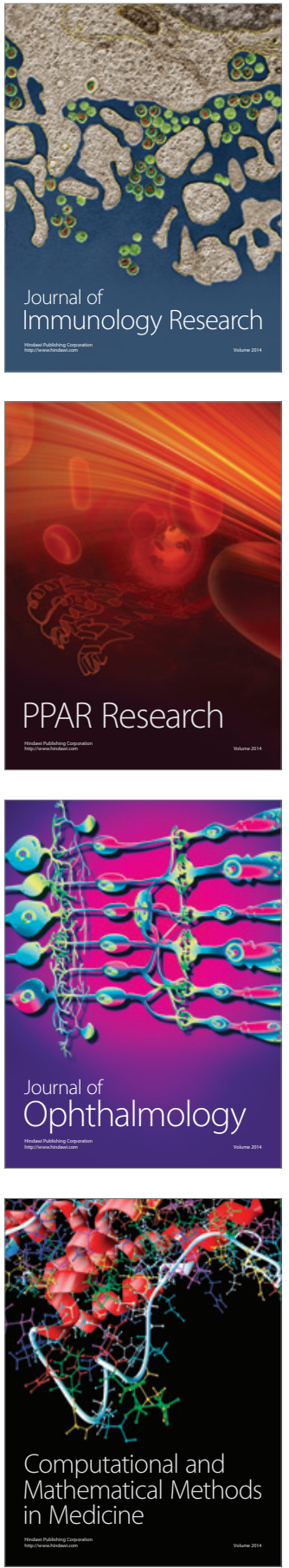

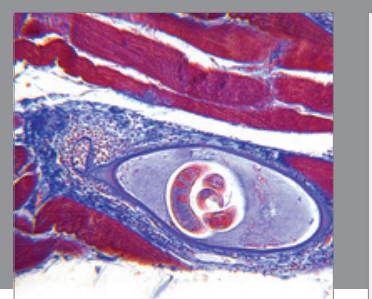

Gastroenterology Research and Practice

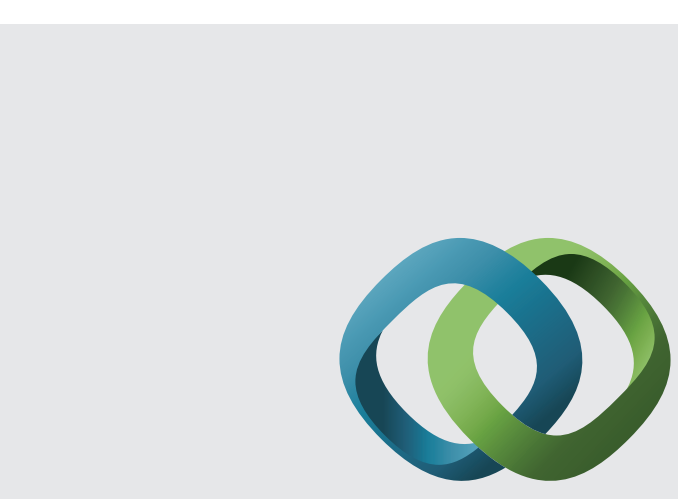

\section{Hindawi}

Submit your manuscripts at

http://www.hindawi.com
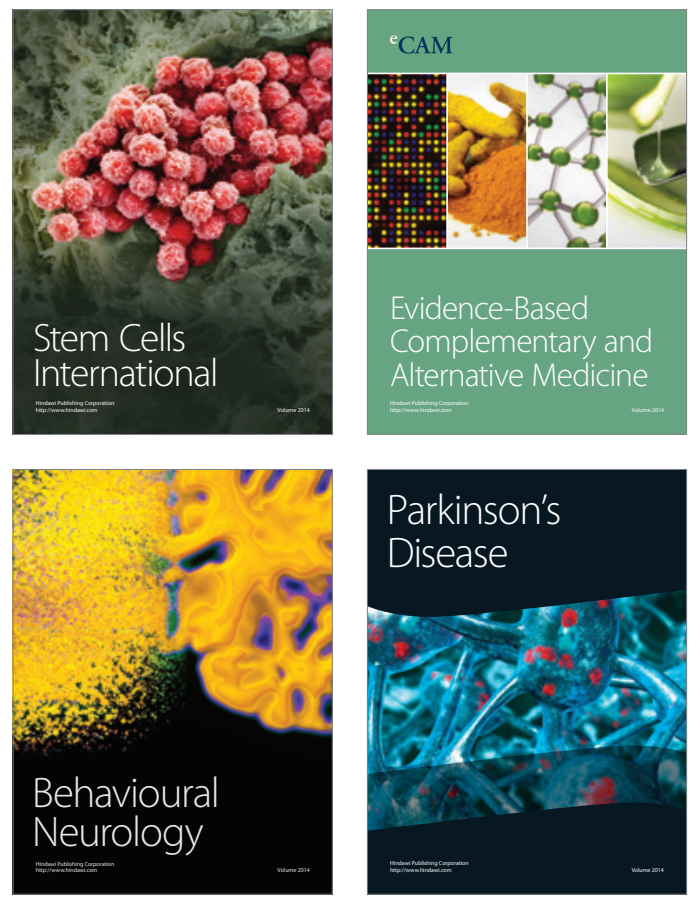
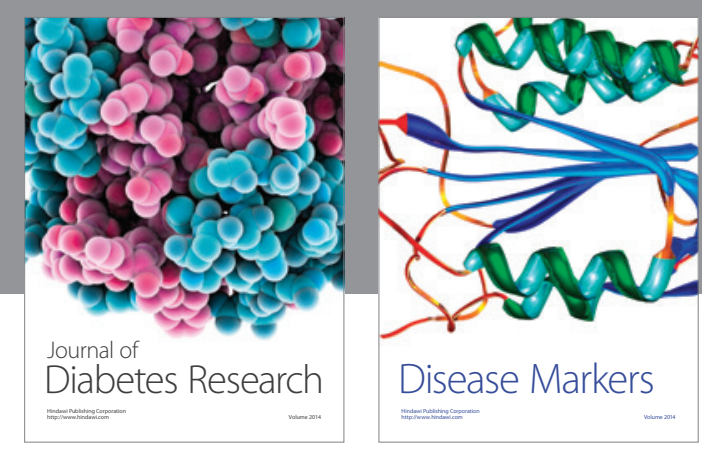

Disease Markers
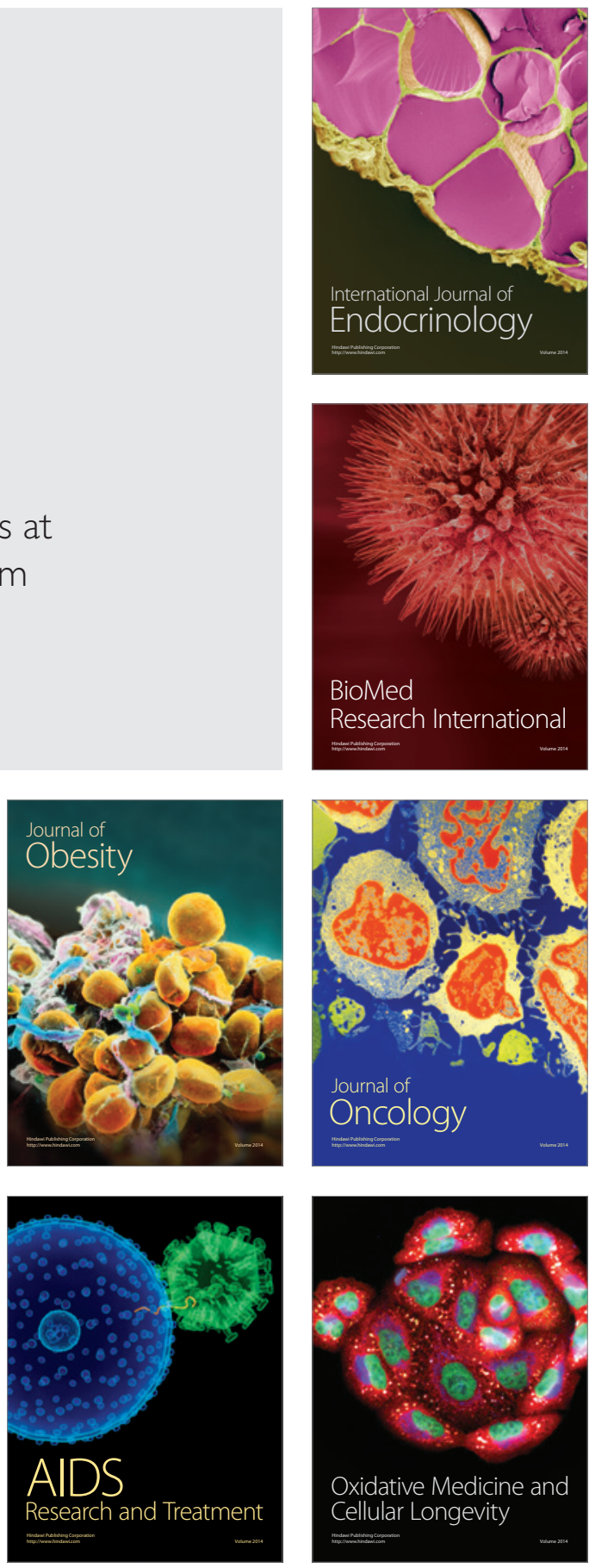